\title{
Parathyroid hormone and plasma phosphate are predictors of soluble $\alpha$-klotho levels in adults of European descent
}

Nasser A. Dhayat ${ }^{1}$, Menno Pruijm ${ }^{2}$, Belen Ponte ${ }^{3}$, Daniel Ackermann ${ }^{1}$, Alexander Benedikt

Leichtle $^{4,5}$, Olivier Devuyst ${ }^{6}$, Georg Ehret ${ }^{7}$, Idris Guessous ${ }^{8}$, Antoinette Pechère-Bertschi ${ }^{9}$, Johanne Pastor $^{10}$, Pierre-Yves Martin ${ }^{3}$, Michel Burnier ${ }^{2}$, Georg-Martin Fiedler ${ }^{4}$, Bruno Vogt ${ }^{1}$, Orson W. Moe ${ }^{10}$, Murielle Bochud ${ }^{11, *}$, Daniel G. Fuster ${ }^{1, *}$

*Contributed equally

${ }^{1}$ Department of Nephrology and Hypertension, Inselspital, Bern University Hospital, University of Bern, Switzerland, ${ }^{2}$ Nephrology Service, Lausanne University Hospital, Lausanne, Switzerland, ${ }^{3}$ Nephrology Service, Department of Specialties of Internal Medicine, Geneva University Hospital, Geneva, Switzerland, ${ }^{4}$ Department of Laboratory Medicine, Inselspital, Bern University Hospital, University of Bern, Switzerland, ${ }^{5}$ Insel Data Science Center, Inselspital, Bern University Hospital, University of Bern, Switzerland, ${ }^{6}$ Institute of Physiology, University of Zurich, ${ }^{7}$ Cardiology Service, Department of Specialties of Internal Medicine, Geneva University Hospital, Geneva, Switzerland, ${ }^{8}$ Division of Primary Care Medicine, Geneva University Hospital, Geneva, Switzerland, ${ }^{9}$ Endocrinology Service, Department of Specialties of Internal Medicine, Geneva University Hospital, Geneva, Switzerland, ${ }^{10}$ Charles and Jane Pak Center of Mineral Metabolism and Clinical Research, Department of Physiology and Department of Internal Medicine, University of Texas Southwestern Medical Center, Dallas, Texas, USA, ${ }^{11}$ Center for Primary Care and Public Health (Unisanté), University of Lausanne, Lausanne, Switzerland.

\section{Corresponding author and person to whom reprint requests should be addressed:}

Daniel G. Fuster, Department of Nephrology and Hypertension, Inselspital, Bern University Hospital, University of Bern, Freiburgstrasse 15, 3010 Bern, Switzerland, Email: daniel.fuster@insel.ch, Phone: +41-31-6323144, Fax: +41-31-6329734 journals.permissions@oup.com. jc.2019-40040. See endocrine.org/publications for Accepted Manuscript disclaimer and additional information. 
Keywords: soluble $\alpha$-klotho, parathyroid hormone, phosphate

DISCLOSURE STATEMENT: DGF has served as a consultant for Otsuka Pharmaceuticals and received unrestricted research funding from Novartis, Abbvie and Otsuka Pharmaceuticals. OWM served on Scientific or Medical Advisory Boards for Allena, Ardelyx, Genzyme-Sanofi, Alnylam, and Triceda. 


\begin{abstract}
Context $\alpha$-klotho is an integral membrane protein, that serves as a co-receptor for fibroblast growth factor 23 (FGF23) in conjunction with cognate fibroblast growth factor receptors. Proteolytic cleavage sheds the ectodomain of $\alpha$-klotho (soluble $\alpha$-klotho) as an endocrine substance into blood, urine and cerebrospinal fluid.
\end{abstract}

Objective To study the relationship of soluble $\alpha$-klotho to mineral metabolism in the general population with mainly preserved kidney function.

Design Cross-sectional analysis of the associations between soluble $\alpha$-klotho with laboratory markers of markers of mineral metabolism in a population-based cohort.

Setting Three centers in Switzerland including 1128 participants.

Measures Soluble full-length $\alpha$-klotho levels by a specific immunoassay and markers of mineral metabolism.

Results The median serum level of soluble $\alpha$-klotho was $15.0 \mathrm{pmol} / \mathrm{L}$. Multivariable analyses using $\alpha$-klotho as outcome variable revealed a sex-by-parathyroid hormone (PTH) interaction: In men, PTH was positively associated with $\alpha$-klotho levels whereas this association was negative in women. Plasma phosphate associated with soluble $\alpha$-klotho levels in an agedependent manner, changing from a positive association in young adults gradually to a negative association in the elderly. The decline of $1,25(\mathrm{OH})_{2}$ vitamin $\mathrm{D}_{3}$ levels in parallel to the gradual impairment of kidney function was greatly attenuated in the setting of high circulating soluble $\alpha$-klotho levels.

Conclusions Soluble $\alpha$-klotho level is associated with plasma phosphate in an age-dependent manner and with PTH in a sex-dependent manner. Furthermore, our data reveal soluble $\alpha$-klotho as a modulator of $1,25(\mathrm{OH})_{2}$ vitamin $\mathrm{D}_{3}$ levels in individuals with preserved renal function. 


\section{INTRODUCTION}

$\alpha$-klotho is a single-pass transmembrane protein that is expressed in renal tubular epithelia, the parathyroid gland, the brain choroid plexus and the hippocampus. The integral membrane protein $\alpha$-klotho serves as a scaffold with cognate fibroblast growth factor receptors (FGFRs), including FGFR1c, FGFR3c and FGFR4, and is critical for FGF23 action in FGF23 target tissues (1). Loss of $\alpha$-klotho in mice results in premature multi-organ failure with reduced lifespan, increased blood pressure due to impaired endothelium-mediated vasodilation and multiple organ defects such as ectopic calcifications, osteoporosis, hypogonadism, neurodegeneration and lung parenchymal degenerative changes (2). Alpha-klotho-deficient mice exhibit hypercalcemia, hyperphosphatemia and increased $1,25-(\mathrm{OH})_{2}$ vitamin D levels. The phenotype of $\alpha$-klotho deficient mice is virtually identical to FGF23 null mice, indicating that both act along similar pathways (3). In humans, homozygous loss-of-function mutations in $\alpha$-klotho cause a syndrome resembling familial tumoral calcinosis, characterized by ectopic calcifications and severe hypercalcemia and hyperphosphatemia (4).

Proteolytic cleavage of the transmembrane $\alpha$-klotho by members 10 and 17 of the A desintegrin and metalloproteinase (ADAM) family, and the beta-secretase beta-APP-1, sheds the ectodomain of $\alpha$-klotho (soluble $\alpha$-klotho) as an endocrine substance into blood, urine and cerebrospinal fluid $(5,6)$. Circulating soluble $\alpha$-klotho is mainly of renal origin $(7,8)$. Soluble $\alpha$-Klotho lacks FGFR co-receptor activity and can act independently of FGF23 through Wnt, growth factor and TGF- $\beta$ pathways, possibly by modulation of lipid raft signaling, as well as direct action on renal phosphate and calcium transporters via intrinsic glycosidase activity (913); an enzymatic activity that is debated (14). The same study provided an alternative view by demonstrating that soluble $\alpha$-klotho in very high concentrations in vitro can serve as a coreceptor for FGF23 in conjunction with FGFRs suggesting that the pleiotropic effects of soluble $\alpha$-klotho may also be dependent on FGF23 (14). 
Reduced renal $\alpha$-klotho expression and reduced circulating $\alpha$-klotho levels were found in acute and chronic kidney disease models, hormonal hypertension, metabolic syndrome and diabetes in rodents (15-17). Low $\alpha$-klotho is not a mere biomarker but pathogenic as restoration of $\alpha$ klotho in experimental rodent chronic kidney disease (CKD) models ameliorated kidney disease and extra-renal complications in rodents $(16,18)$. This hoists the significance of $\alpha$-klotho deficiency in CKD from diagnostic and prognostic to therapeutic.

Relatively little is known about the factors that regulate circulating $\alpha$-klotho levels in humans and the available data are conflicting $(17,19-27)$. Current commercial ELISAs employed for the determination of soluble $\alpha$-klotho in humans have certain limitations, including crossreactivity with other serum proteins, loss of efficiency after repeated freeze-thawing of samples, loss of sensitivity with vintage of storage resulting in discrepant results with fresh versus stored samples (28). These limitations likely explain some of the discrepancies reported in the literature. An assay for $\alpha$-klotho in serum and urine was developed and characterized, based on an immunoprecipitation-immunoblotting (IP-IB) assay, that overcomes a number of the limitations of the commercial ELISAs (28). This assay measures the full-length $130 \mathrm{kDa}$, secreted form of $\alpha$-klotho specifically. Using this assay, we conducted a cross-sectional analysis in a large, multicenter, population-based cohort to investigate the association of mineral metabolism markers with serum $\alpha$-klotho levels (29).

\section{MATERIALS AND METHODS}

\section{Study population}

SKIPOGH is a multicenter family-based cross-sectional study exploring the role of genes and kidney hemodynamics in blood pressure regulation and kidney function in the general adult population (29). Inclusion criteria were: (1) a minimum age of 18 years; (2) European ancestry; (3) having at least one and ideally three first-degree family members willing to participate; and

(4) a written informed consent. The SKIPOGH study adhered to the Declaration of Helsinki 
and was approved by the institutional ethical committees of each participating University hospital. Of a total of 1128 SKIPOGH participants, 118 participants were excluded from the final analysis for the following reasons: (1) primary hyperparathyroidism or history of parathyroidectomy $(\mathrm{n}=2)$; (2) chronic liver disease $(\mathrm{n}=1)$; (3) active malignant diseases $(\mathrm{n}=10)$; (4) pregnancy $(n=1)$; (5) intake of the following drugs: over-the-counter or prescribed calcium and/or vitamin D supplements $(\mathrm{n}=22)$, bisphosphonates $(\mathrm{n}=2)$, glucocorticoids or mineralocorticoids $(n=5)$, antiepileptics $(n=2)$, loop diuretics $(n=6)$, thiazide diuretics $(n=63)$, potassium sparing diuretics $(n=5)$, and desmopressin $(n=1)$. Of the remaining 1010 participants, 98 serum samples were lacking for the analysis of $\alpha$-klotho, leaving 912 participants from 269 distinct families and three study centers available for the final analysis.

\section{Data collection and measurements}

Absolute urinary creatinine excretion was used as the criterion for completeness of 24-hour urine collections, using recently published data from the cross-sectional Swiss Salt Study (SSS) $(29,30)$. Urine collections were considered as complete if the total 24-hour creatinine excretion was within centiles 2.5 and 97.5. Fasting morning electrolytes and serum creatinine were measured by standard clinical laboratory methods in each center. Plasma FGF23, PTH, 25$(\mathrm{OH})$ vitamin $\mathrm{D}_{3}$ and $1,25-(\mathrm{OH})_{2}$ vitamin $\mathrm{D}_{3}$ were determined centrally for all study participants as single measurements. Plasma FGF23 was measured in the laboratory of TECOmedical AG (Sissach, Switzerland) by the second generation C-terminal assay (Immutopics, San Clemente, CA) $(29,31)$. Lower detection limit of the assay is $1.5 \mathrm{RU} / \mathrm{ml}$, intra- and inter-assay coefficients of variation are 1.4-2.4\% and 2.4-4.7\%, respectively. Plasma PTH, 25-(OH) vitamin $\mathrm{D}_{3}$ and 1,25- $(\mathrm{OH})_{2}$ vitamin $\mathrm{D}_{3}$ were measured in the Center of Laboratory Medicine, Inselspital, Berne: Plasma intact PTH by electrochemiluminescence immunoassay (ECLIA) on a Roche Modular E170 (Roche Diagnostics AG, Rotkreuz, Switzerland), plasma 25-(OH) vitamin $\mathrm{D}_{3}$ by a direct, competitive chemiluminescence-immunoassay (CLIA) on a LIAISON® Analyzer (DiaSorin 
S.p.A., Saluggia (VC), Italy) and plasma $1,25-(\mathrm{OH})_{2}$ vitamin $\mathrm{D}_{3}$ by a competitive enzymimmunoassay on a Multilabel Counter Victor 3 (PerkinElmer, Inc., Waltham, USA). Intra- and inter-assay coefficients of variation are $1.1-2.0 \%$ and $2.5-3.4 \%$ for plasma PTH, $4.1-5.8 \%$ and 6.6-7.1\% for plasma $25-(\mathrm{OH})$ vitamin $\mathrm{D}_{3}$ and $<8-<10 \%$ for plasma $1,25-(\mathrm{OH})_{2}$ vitamin $\mathrm{D}_{3}$ respectively.

For the determination of soluble $\alpha$-klotho, we used serum samples obtained while fasting in the morning, frozen the day of blood draw and kept at $-80{ }^{\circ} \mathrm{C}$ thereafter. All serum samples were thawed only once, for determination of serum $\alpha$-klotho levels. Soluble serum $\alpha$-klotho levels by a quantitative immunoprecipitation - immunoblotting assay, as described in detail $(28,32)$. Briefly, $50 \mu \mathrm{L}$ of serum were diluted with KRH buffer [ $25 \mathrm{mM}$ HEPES-NaOH (pH 7.4), 120 $\left.\mathrm{mM} \mathrm{NaCl}, 5 \mathrm{mM} \mathrm{KCl}, 1.2 \mathrm{mM} \mathrm{MgSO}_{4}, 1.3 \mathrm{mM} \mathrm{CaCl}_{2}, 1.3 \mathrm{mM} \mathrm{KH}_{2} \mathrm{PO}_{4}\right]$ to a final volume of $0.5 \mathrm{~mL}$ and incubated overnight at $4^{\circ} \mathrm{C}$ with $2 \mu \mathrm{g}$ of $\mathrm{Fab} 48$ (alias sb106), which recognizes both HEK293 cell-expressed human full-length membrane $\alpha$-klotho as well as the soluble $\alpha$ klotho ectodomain. Fab sb48-FLAG - $\alpha$-klotho complexes were immunoprecipitated with ANTI-FLAG $^{\circledR}$ M2 Affinity Agarose Gel beads (Sigma-Aldrich, St-Louis Mi.), fractionated by SDS-PAGE and transferred to nitrocellulose membranes. Immunoblotting with anti- $\alpha$ klotho antibody KM2076 (Transgenic Inc., Kobe, Japan) was used to detect the soluble $\alpha$-klotho ectodomain ( 130 kDa). The $130 \mathrm{kDa}$ bands were scanned, and density was compared with internal standards of known amounts of $\alpha$-klotho (murine klotho isoform, obtained from a CHO cell line that stably expresses the full-length klotho isoform 1, gift from Kyowa Hakko Kogyo Co. Ltd. (33)) to calculate final $\alpha$-klotho concentration in individual serum samples. Intra- and inter-assay coefficients of the assay are 8-18\% and 4.8-16.6\%, respectively.

The creatinine-based CKD-EPI 2009 equation was used to estimate the glomerular filtration rate (eGFRcr) (34). Tubular maximum reabsorption of phosphorus per glomerular filtration rate (TmP/GFR in mmol/l) was calculated with the algorithm derived by Kenny and Glen $(35,36)$. 


\section{Statistical analysis}

All statistical analyses were conducted using the R software, version 3.2.2 (37). The shape of the distribution of each continuous variable was visually inspected and square-root-, log- or inverse-transformations were applied to better approximate a normal distribution of the residuals for statistical analyses. All statistical tests were two-sided and a $P$ value $<0.05$ was considered statistically significant, including for two-way interaction analyses.

We assessed the univariable association between the linear and quadratic terms of explanatory variables of interest with square-root transformed soluble $\alpha$-klotho as outcome variable, determined as an appropriate transformation. All models were calculated by mixed-effects linear regression with day of blood sampling and family nested within center as the random effect structure. Quadratic terms of the explanatory variables were not found to be significantly associated with the outcome variable. All models were then extended to multivariable analyses by adding the following explanatory variables and their interaction terms as fixed effects: sex, age, BMI, eGFRcr, study center, and serum sample freezing time. Fixed effects and statistically significant interaction terms were kept in the final models, while keeping hierarchically sound models. Models were validated by graphical analysis for homogeneity of variance, normality of residuals and highly influential observations. Additional regression analyses were conducted exploring the univariate association between soluble $\alpha$-klotho, as explanatory variable, with transformed laboratory parameters of mineral metabolism as outcome variables while keeping the random effect structure in all models. Multivariable models were derived thereof by adding sex, age, body mass index, eGFRcr, study center, and the serum sample freezing time to soluble $\alpha$-klotho (as the explanatory variable of interest). All models were created with continuous explanatory variables mean centered at zero to minimize collinearity problems. Selected multivariable regression models were plotted to illustrate the relationship between the explanatory variable of interest with the outcome variable while holding the effect of all other covariables in the model constant using the statistical R package visreg (38). It should be noted 
that these plots provide no confidence bands as the created models does not offer predictions about the uncertainty of random effects. 


\section{RESULTS}

\section{Characteristics of the study population}

Characteristics of the study population are shown in Table 1. Participants were $18-90$ years old, with a median age of 45.7 years $\left(25^{\text {th }}-75^{\text {th }}\right.$ percentile $30.2-58.0$ years $)$, and $52.3 \%$ were women. Median eGFRcr (glomerular filtration rate estimated based on creatinine equation CKD-EPI 2009) was $98.4 \mathrm{~mL} / \mathrm{min}$ per $1.73 \mathrm{~m}^{2}$. Of note, only $2.3 \%$ of study participants had an eGFRcr $<60 \mathrm{~mL} / \mathrm{min}$ per $1.73 \mathrm{~m}^{2}$. The distribution of soluble $\alpha$-klotho levels was right skewed with a median serum level of $15.0 \mathrm{pmol} / \mathrm{L}\left(25^{\text {th }}-75^{\text {th }}\right.$ percentile $\left.10.0-21.0 \mathrm{pmol} / \mathrm{L}\right)($ Fig. $1 \mathrm{~A}, \mathrm{C})$. After square root transformation, soluble $\alpha$-klotho residual values displayed a near normal distribution, both in the entire study population but also within both sex subgroups (Fig. 1B, D). Soluble $\alpha$-klotho levels were slightly higher in women (median $15.3 \mathrm{pmol} / \mathrm{L}, 25^{\text {th }}-75^{\text {th }}$ percentile $10.0-22.0 \mathrm{pmol} / \mathrm{L}$ ) than in men (median $13.9 \mathrm{pmol} / \mathrm{l}, 25^{\text {th }}-75^{\text {th }}$ percentile $9.9-20.0 ; P$ $=0.018$, Welch t-test, Fig. 1E), and higher in individuals aged $\leq 30$ years (median $16.0 \mathrm{pmol} / \mathrm{l}$, $25^{\text {th }}-75^{\text {th }}$ percentile $10.2-22.0$ ) than in those aged $\geq 60$ years old (median $14.0 \mathrm{pmol} / 1,25^{\text {th }}-75^{\text {th }}$ percentile 9.6-20.0; $P=0.028$, Welch t-test). In a simple univariable linear regression analysis higher soluble $\alpha$-klotho levels were found at higher eGFRcr $(\beta: 0.0063, P=0.00096$, Fig. $1 \mathrm{~F})$.

\section{Association analyses with soluble $\alpha$-klotho as outcome variable}

We first performed association analyses between the population characteristics as explanatory (i.e. independent) variables and square root transformed soluble $\alpha$-klotho as outcome (i.e. dependent) variable. All models were calculated by mixed-effects linear regression (Table 2). In univariable analyses, positive correlates of soluble $\alpha$-klotho were female sex $(\beta: 0.1507, P=$ 0.0035), eGFRcr $(\beta: 0.0044, P=0.0051)$ and plasma calcium $(\beta: 0.6672, P=0.042)$, whereas age $(\beta$ : $-0.0038, P=0.015)$ and BMI $(\beta:-0.0172, P=0.01)$ were negatively associated with soluble $\alpha$-klotho levels. In a next step, we conducted multivariable analyses by mixed-effects 
linear regression using indicated predictor variables and soluble $\alpha$-klotho as outcome variable. As shown in Table 2, multivariable analyses revealed a significant sex-by PTH interaction for their association with soluble $\alpha$-klotho $(\beta$ : $-0.0111, P=0.0045)$. Visualization of this interaction in Fig. 2A reveals that the association of PTH with soluble $\alpha$-klotho levels is sex-specific, being positive in men and negative in women. Additionally, we also discovered a significant agedependent association between plasma phosphate and soluble $\alpha$-klotho $(\beta$ : $-0.0220, P=0.011)$. As depicted in Fig. 2B, in young adults the association is positive but then becomes progressively negative with increasing age. All other associations with soluble $\alpha$-klotho as outcome variable remained no longer significant after multivariable adjustment.

\section{Association analyses with soluble $\alpha$-klotho as predictor variable}

We then performed association analyses with soluble serum $\alpha$-klotho as predictor variable and laboratory parameters of calcium-phosphate metabolism as outcome variables using mixedeffects linear regression (Table 3). In univariable analyses eGFRcr $(\beta: 3.47, P=0.0018)$ and plasma calcium $(\beta$ : 0.0002, $P=0.036)$ were positively associated with soluble $\alpha$-klotho. In multivariable regression analyses (Table 3), soluble $\alpha$-klotho displayed a significant interaction with eGFRcr for the association with $1,25(\mathrm{OH})_{2}$ vitamin $\mathrm{D}_{3}(\beta:-0.0009, P=0.029)$, i.e. the positive association of eGFRcr with $1,25(\mathrm{OH})_{2}$ vitamin $\mathrm{D}_{3}$ was significantly influenced by circulating $\alpha$-klotho levels (Fig. 3A). Similarly, we observed an inverse association of body mass index with plasma phosphate $(\beta: 0.0004, P=0.011)$ that was dependent on circulating $\alpha-$ klotho levels (Fig. 3B). 


\section{DISCUSSION}

We quantified soluble $\alpha$-klotho levels using a specific IP-IB immunoassay in a wellcharacterized population-based sample of individuals with largely preserved renal function. Our analysis revealed levels of circulating $\alpha$-klotho in serum in the double digit picomolar range (median $15 \mathrm{pmol} / \mathrm{L}$ ) - same order of magnitude as what has been reported previously with this assay (28). In univariable analyses, we observed several significant associations of eGFR and mineral metabolism markers with soluble $\alpha$-klotho levels, which partially corroborate with previous findings $(23,26,39-41)$. In contrast to previous small studies, the large data set enabled us to adjust for several potential confounders in multivariable analysis. We found a sex-specific association of $\alpha$-klotho with PTH in the general adult population, with a negative association in women and a positive one in men. In mice, androgens increase and estrogens decrease $\alpha$-klotho mRNA and protein expression in the kidney $(42,43)$, but to our knowledge, the impact of sex hormones on soluble $\alpha$-klotho has not been studied in rodents or humans.

Parathyroid glands express $\alpha$-klotho, but mice with parathyroid-specific deletion of $\alpha$-klotho have a normal phenotype and survival, normal serum PTH and calcium and unaltered expression of the PTH gene in parathyroid tissue (44). However, combined deletion of $\alpha$-klotho and the calcium-sensing receptor (CASR) in parathyroid glands results in significantly higher serum PTH, FGF23, and 1,25 $(\mathrm{OH})_{2}$ vitamin $\mathrm{D}_{3}$ levels compared to mice with a parathyroidspecific deletion of the CASR alone, indicating that $\alpha$-klotho expressed in the parathyroid gland is a negative regulator of PTH synthesis that works synergistically with CaSR (45). Another model indicates that $\alpha$-klotho directly interacts with the PTH receptor and thereby attenuates PTH signaling in target tissues (46). While target organ resistance to PTH would be consistent with a positive association of circulating $\alpha$-klotho levels with PTH, an inverse correlation between soluble $\alpha$-klotho and PTH would be expected if $\alpha$-klotho acts as a suppressor of PTH secretion in vivo. Our data indicate that the association of PTH and $\alpha$-klotho is complex and modified by sex-related factors. The cause of the sex-specific association observed in the cohort 
cannot be answered through cross-sectional analyses like our study and remains to be tested using longitudinal data.

The lack of an association with GFR contrasts a previous study in a small group of healthy volunteers and patients with much more severe reductions of GFR (CKD stages I-V) employing the same immunoassay which concluded that there was a gradual decrease of $\alpha$-klotho in serum with declining GFR (28). Importantly, there is considerable overlap of serum $\alpha$-klotho levels between healthy volunteers and CKD stages I and II. Also, due to the small number of individuals, adjustment for potential confounders was not possible in that study. In univariable analyses, we similarly observed a significant association of GFR with soluble $\alpha$-klotho even within the small and mostly normal range of GFR, but the association was not significant after multivariable adjustment. The most important point is that the individuals in our cohort had normal renal function, and only an extremely small fraction (2.3\%) had a GFR $<60 \mathrm{~mL} / \mathrm{min}$ per $1.73 \mathrm{~m}^{2}$. Hence, it is entirely possible that circulating $\alpha$-klotho levels indeed decline marginally in CKD I and II but can be buried with the other determinants, but in CKD stages III, IV and $\mathrm{V}$, the association remains significant even after adjustment for multiple confounders.

As expected for a circulating factor involved in phosphate homeostasis, plasma phosphate correlated with circulating $\alpha$-klotho levels in our cohort (8). The association was strongly agedependent (positive in young and negative in older adults) and not paralleled by correlations of soluble $\alpha$-klotho levels with TmP/GFR or fractional excretion of phosphate. Thus, soluble $\alpha$ klotho-mediated differences in renal phosphate handling are unlikely to account for this association. Rather the result suggests that plasma phosphate influences soluble $\alpha$-klotho levels, possibly by affecting its synthesis in the kidney. Phosphate loading in rodents consistently reduced circulating serum $\alpha$-klotho but this was not observed in humans (47). A recent interventional study demonstrated an increase in circulating $\alpha$-klotho levels in healthy 
volunteers under a high phosphate diet (32). Alternatively, soluble $\alpha$-klotho may affect extrarenal handling of phosphate in bone or gut in an age-dependent manner.

In a previous analysis of this cohort, we discovered that the decline of $1,25(\mathrm{OH})_{2}$ vitamin $\mathrm{D}_{3}$ with falling GFR is closely paralleled and significantly associated by a rise in FGF23, a negative regulator of $1,25(\mathrm{OH})_{2}$ vitamin $\mathrm{D}_{3}$ synthesis in the proximal tubule (29). Our data now demonstrate that the well-known GFR dependence of $1,25(\mathrm{OH})_{2}$ vitamin $\mathrm{D}_{3}$ levels is significantly influenced by soluble $\alpha$-klotho. In the setting of high soluble $\alpha$-klotho, the GFRdependent decline of $1,25(\mathrm{OH})_{2}$ vitamin $\mathrm{D}_{3}$ is greatly attenuated. This finding suggests that $\alpha$ klotho antagonizes the FGF23-mediated downregulation of $1,25(\mathrm{OH})_{2}$ vitamin $\mathrm{D}_{3}$ in early CKD. Since soluble $\alpha$-klotho and $1,25(\mathrm{OH})_{2}$ vitamin $\mathrm{D}_{3}$ are both kidney-tubule derived substances, the finding could also be explained by differences in tubular function at an individual level of GFR: Preserved tubular function despite reduction in GFR would be associated with normal or near normal circulating $\alpha$-klotho and $1,25(\mathrm{OH})_{2}$ vitamin $\mathrm{D}_{3}$ levels. On the other hand, circulating $\alpha$-klotho and 1,25 $(\mathrm{OH})_{2}$ vitamin $\mathrm{D}_{3}$ levels maybe reduced due to tubular dysfunction despite preserved GFR. Quantification of circulating $\alpha$-klotho in different CKD subgroups (predominant tubule-interstitial versus isolated glomerular disease) could shed more light on the interaction between $\alpha$-klotho and $1,25(\mathrm{OH})_{2}$ vitamin $\mathrm{D}_{3}$. Ultimately, however, interventional studies will be needed to understand the underlying mechanisms.

Our study reproduces the previous observation of an inverse association of plasma phosphate with BMI (48). Both increased PTH and FGF23 levels have been reported in individuals with increased fat mass and adiposity (49-51). Our results indicate that the negative association of BMI with plasma phosphate is modulated by circulating $\alpha$-klotho, possibly by either affecting PTH / FGF23 signalling at target organs or alternatively by altering PTH / FGF23 secretion.

Our study has several limitations. The cross-sectional design only allows to infer associations but not causal relationships. Also, no direct GFR measurements based on exogenous filtration 
markers were available. In addition, while the IB-IP assay is very specific, it is not as quantitative than ELISA. Hence, it is possible that we missed factors weakly associated with soluble $\alpha$-klotho in the current study.

In summary, using a specific novel immunoassay for soluble $\alpha$-klotho, our study reveals that plasma phosphate - in an age-dependent manner - and parathyroid hormone - in a sex-dependent manner - are associated with soluble $\alpha$-klotho levels in humans. Furthermore, our data reveal soluble $\alpha$-klotho as a modulator of $1,25(\mathrm{OH})_{2}$ vitamin $\mathrm{D}_{3}$ levels in individuals with preserved renal function.

\section{Declaration of interest}

The authors declare that there is no conflict of interest that could be perceived as prejudicing the impartiality of the research reported.

\section{FUNDING}

SKIPOGH was supported by a grant from the Swiss National Science Foundation (grant \# FN 33CM30-124087 to MB). DGF was supported by the Swiss National Centre of Competence in Research NCCR TransCure and the Swiss National Science Foundation (grants \# 31003A_135503, 31003A_152829 and 33IC30_166785/1). OWM was supported by the

National Institutes of Health (O’Brien Kidney Research Center P30 DK-079328; R01 DK081423; R01 DK091392), the American Heart Foundation, the Charles Pak Foundation Innovative Research Award, and the Seldin-Pak Fund for Human Metabolic Research.

\section{AUTHORS' CONTRIBUTION}

NAD, BV, OWM, MB and DGF conceived and planned the study. MP, BP, DA, GE, IG, APB, PYM, MB recruited patients into the study. ABL, OD, JP and GMF performed laboratory 
analyses. NAD and DGF performed statistical analyses. NAD, OWM, MB and DGF wrote the manuscript with input from all authors. All authors approved the final version of the manuscript.

\section{ACKNOWLEDGMENTS}

We thank the research nurses Marie-Odile Levy, Guler Gök-Sogüt, Ulla Schüpbach and

Dominique Siminski for data collection and Sandrine Estoppey for her invaluable help in logistics and database management. 


\section{REFERENCES}

1. Urakawa I, Yamazaki Y, Shimada T, Iijima K, Hasegawa H, Okawa K, Fujita T, Fukumoto S, Yamashita T 2006 Klotho converts canonical FGF receptor into a specific receptor for FGF23. Nature 444:770-774

2. Kuro-o M, Matsumura Y, Aizawa H, Kawaguchi H, Suga T, Utsugi T, Ohyama Y, Kurabayashi M, Kaname T, Kume E, Iwasaki H, Iida A, Shiraki-Iida T, Nishikawa S, Nagai R, Nabeshima YI 1997 Mutation of the mouse klotho gene leads to a syndrome resembling ageing. Nature 390:45-51

3. Shimada T, Kakitani M, Yamazaki Y, Hasegawa H, Takeuchi Y, Fujita T, Fukumoto S, Tomizuka K, Yamashita T 2004 Targeted ablation of Fgf23 demonstrates an essential physiological role of FGF23 in phosphate and vitamin D metabolism. J Clin Invest 113:561-568

4. Ichikawa S, Imel EA, Kreiter ML, Yu X, Mackenzie DS, Sorenson AH, Goetz R, Mohammadi M, White KE, Econs MJ 2007 A homozygous missense mutation in human KLOTHO causes severe tumoral calcinosis. J Musculoskelet Neuronal Interact 7:318-319

5. Chen CD, Podvin S, Gillespie E, Leeman SE, Abraham CR 2007 Insulin stimulates the cleavage and release of the extracellular domain of Klotho by ADAM10 and ADAM17. Proc Natl Acad Sci U S A 104:19796-19801

6. Bloch L, Sineshchekova O, Reichenbach D, Reiss K, Saftig P, Kuro-o M, Kaether C 2009 Klotho is a substrate for alpha-, beta- and gamma-secretase. FEBS Lett 583:3221-3224

7. Lindberg K, Amin R, Moe OW, Hu MC, Erben RG, Ostman Wernerson A, Lanske B, Olauson H, Larsson TE 2014 The Kidney Is the Principal Organ Mediating Klotho Effects. J Am Soc Nephrol

8. Hu MC, Shi M, Zhang J, Pastor J, Nakatani T, Lanske B, Razzaque MS, Rosenblatt KP, Baum MG, Kuro-o M, Moe OW 2010 Klotho: a novel phosphaturic substance acting as an autocrine enzyme in the renal proximal tubule. Faseb J 24:34383450

9. Cha SK, Ortega B, Kurosu H, Rosenblatt KP, Kuro OM, Huang CL 2008 Removal of sialic acid involving Klotho causes cell-surface retention of TRPV5 channel via binding to galectin-1. Proc Natl Acad Sci U S A 105:9805-9810

10. Kurosu H, Yamamoto M, Clark JD, Pastor JV, Nandi A, Gurnani P, McGuinness OP, Chikuda H, Yamaguchi M, Kawaguchi H, Shimomura I, Takayama Y, Herz J, Kahn CR, Rosenblatt KP, Kuro-o M 2005 Suppression of aging in mice by the hormone Klotho. Science 309:1829-1833

11. Liu H, Fergusson MM, Castilho RM, Liu J, Cao L, Chen J, Malide D, Rovira, II, Schimel D, Kuo CJ, Gutkind JS, Hwang PM, Finkel T 2007 Augmented Wnt signaling in a mammalian model of accelerated aging. Science 317:803-806

12. Chang Q, Hoefs S, van der Kemp AW, Topala CN, Bindels RJ, Hoenderop JG 2005 The beta-glucuronidase klotho hydrolyzes and activates the TRPV5 channel. Science 310:490-493

13. Dalton G, An SW, Al-Juboori SI, Nischan N, Yoon J, Dobrinskikh E, Hilgemann DW, Xie J, Luby-Phelps K, Kohler JJ, Birnbaumer L, Huang CL 2017 Soluble klotho binds monosialoganglioside to regulate membrane microdomains and growth factor signaling. Proc Natl Acad Sci U S A 114:752-757

14. Chen G, Liu Y, Goetz R, Fu L, Jayaraman S, Hu MC, Moe OW, Liang G, Li X, Mohammadi M 2018 alpha-Klotho is a non-enzymatic molecular scaffold for FGF23 hormone signalling. Nature 553:461-466 
15. Haruna Y, Kashihara N, Satoh M, Tomita N, Namikoshi T, Sasaki T, Fujimori T, Xie P, Kanwar YS 2007 Amelioration of progressive renal injury by genetic manipulation of Klotho gene. Proc Natl Acad Sci U S A 104:2331-2336

16. Wang Y, Sun Z 2009 Klotho gene delivery prevents the progression of spontaneous hypertension and renal damage. Hypertension 54:810-817

17. Koh N, Fujimori T, Nishiguchi S, Tamori A, Shiomi S, Nakatani T, Sugimura K, Kishimoto T, Kinoshita S, Kuroki T, Nabeshima Y 2001 Severely reduced production of klotho in human chronic renal failure kidney. Biochem Biophys Res Commun 280:1015-1020

18. Hu MC, Shi M, Zhang J, Quinones H, Griffith C, Kuro-o M, Moe OW 2011 Klotho deficiency causes vascular calcification in chronic kidney disease. J Am Soc Nephrol 22:124-136

19. Akimoto T, Kimura T, Watanabe Y, Ishikawa N, Iwazu Y, Saito O, Muto S, Yagisawa T, Kusano E 2013 The impact of nephrectomy and renal transplantation on serum levels of soluble Klotho protein. Transplant Proc 45:134-136

20. Ponte B, Trombetti A, Hadaya K, Ernandez T, Fumeaux D, Iselin C, Martin PY, de Seigneux S 2014 Acute and long term mineral metabolism adaptation in living kidney donors: a prospective study. Bone 62:36-42

21. Devaraj S, Syed B, Chien A, Jialal I 2012 Validation of an immunoassay for soluble Klotho protein: decreased levels in diabetes and increased levels in chronic kidney disease. Am J Clin Pathol 137:479-485

22. Carpenter TO, Insogna KL, Zhang JH, Ellis B, Nieman S, Simpson C, Olear E, Gundberg CM 2010 Circulating levels of soluble klotho and FGF23 in X-linked hypophosphatemia: circadian variance, effects of treatment, and relationship to parathyroid status. J Clin Endocrinol Metab 95:E352-357

23. Seiler S, Rogacev KS, Roth HJ, Shafein P, Emrich I, Neuhaus S, Floege J, Fliser D, Heine GH 2014 Associations of FGF-23 and sKlotho with cardiovascular outcomes among patients with CKD stages 2-4. Clin J Am Soc Nephrol 9:1049-1058

24. Seiler S, Wen M, Roth HJ, Fehrenz M, Flugge F, Herath E, Weihrauch A, Fliser D, Heine GH 2013 Plasma Klotho is not related to kidney function and does not predict adverse outcome in patients with chronic kidney disease. Kidney Int 83:121-128

25. Oh HJ, Nam BY, Lee MJ, Kim CH, Koo HM, Doh FM, Han JH, Kim EJ, Han JS, Park JT, Yoo TH, Kang SW, Han DS, Han SH 2014 Decreased Circulating Klotho Levels in Patients Undergoing Dialysis and Relationship to Oxidative Stress and Inflammation. Perit Dial Int

26. Kim HR, Nam BY, Kim DW, Kang MW, Han JH, Lee MJ, Shin DH, Doh FM, Koo HM, Ko KI, Kim CH, Oh HJ, Yoo TH, Kang SW, Han DS, Han SH 2013 Circulating alpha-klotho levels in CKD and relationship to progression. Am J Kidney Dis 61:899909

27. Yamazaki Y, Imura A, Urakawa I, Shimada T, Murakami J, Aono Y, Hasegawa H, Yamashita T, Nakatani K, Saito Y, Okamoto N, Kurumatani N, Namba N, Kitaoka T, Ozono K, Sakai T, Hataya H, Ichikawa S, Imel EA, Econs MJ, Nabeshima Y 2010 Establishment of sandwich ELISA for soluble alpha-Klotho measurement: Age-dependent change of soluble alpha-Klotho levels in healthy subjects. Biochem Biophys Res Commun 398:513-518

28. Barker SL, Pastor J, Carranza D, Quinones H, Griffith C, Goetz R, Mohammadi M, Ye J, Zhang J, Hu MC, Kuro-o M, Moe OW, Sidhu SS 2015 The demonstration of alphaKlotho deficiency in human chronic kidney disease with a novel synthetic antibody. Nephrol Dial Transplant 30:223-233

29. Dhayat NA, Ackermann D, Pruijm M, Ponte B, Ehret G, Guessous I, Leichtle AB, Paccaud F, Mohaupt M, Fiedler GM, Devuyst O, Pechere-Bertschi A, Burnier M, 
Martin PY, Bochud M, Vogt B, Fuster DG 2016 Fibroblast growth factor 23 and markers of mineral metabolism in individuals with preserved renal function. Kidney Int 90:648-657

30. Forni Ogna V, Ogna A, Vuistiner P, Pruijm M, Ponte B, Ackermann D, Gabutti L, Vakilzadeh N, Mohaupt M, Martin PY, Guessous I, Pechere-Bertschi A, Paccaud F, Bochud M, Burnier M, Swiss Survey on Salt G 2015 New anthropometry-based age- and sex-specific reference values for urinary 24-hour creatinine excretion based on the adult Swiss population. BMC Med 13:40

31. Isakova T, Wahl P, Vargas GS, Gutierrez OM, Scialla J, Xie H, Appleby D, Nessel L, Bellovich K, Chen J, Hamm L, Gadegbeku C, Horwitz E, Townsend RR, Anderson CA, Lash JP, Hsu CY, Leonard MB, Wolf M 2011 Fibroblast growth factor 23 is elevated before parathyroid hormone and phosphate in chronic kidney disease. Kidney Int 79:1370-1378

32. Mohammad J, Scanni R, Bestmann L, Hulter HN, Krapf R 2018 A Controlled Increase in Dietary Phosphate Elevates BP in Healthy Human Subjects. J Am Soc Nephrol 29:2089-2098

33. Imura A, Iwano A, Tohyama O, Tsuji Y, Nozaki K, Hashimoto N, Fujimori T, Nabeshima Y 2004 Secreted Klotho protein in sera and CSF: implication for posttranslational cleavage in release of Klotho protein from cell membrane. FEBS Lett 565:143-147

34. Levey AS, Stevens LA, Schmid CH, Zhang YL, Castro AF, 3rd, Feldman HI, Kusek JW, Eggers P, Van Lente F, Greene T, Coresh J 2009 A new equation to estimate glomerular filtration rate. Ann Intern Med 150:604-612

35. Bijvoet OL, Morgan DB, Fourman P 1969 The assessment of phosphate reabsorption. Clin Chim Acta 26:15-24

36. Kenny AP, Glen AC 1973 Tests of phosphate reabsorption. Lancet 2:158

37. 2015 R Core Team. R: A language and environment for statistical computing. R Foundation for Statistical Computing, Vienna, Austria. URL https://www.Rproject.org/.

38. Breheny P, Burchett W 2013 Visualization of regression models using visreg. R package:1-15

39. Kitagawa M, Sugiyama H, Morinaga H, Inoue T, Takiue K, Ogawa A, Yamanari T, Kikumoto Y, Uchida HA, Kitamura S, Maeshima Y, Nakamura K, Ito H, Makino H 2013 A decreased level of serum soluble Klotho is an independent biomarker associated with arterial stiffness in patients with chronic kidney disease. PLoS One 8:e56695

40. Akimoto T, Yoshizawa H, Watanabe Y, Numata A, Yamazaki T, Takeshima E, Iwazu K, Komada T, Otani N, Morishita Y, Ito C, Shiizaki K, Ando Y, Muto S, Kuro-o M, Kusano E 2012 Characteristics of urinary and serum soluble Klotho protein in patients with different degrees of chronic kidney disease. BMC Nephrol 13:155

41. Pavik I, Jaeger P, Ebner L, Wagner CA, Petzold K, Spichtig D, Poster D, Wuthrich RP, Russmann S, Serra AL 2013 Secreted Klotho and FGF23 in chronic kidney disease Stage 1 to 5: a sequence suggested from a cross-sectional study. Nephrol Dial Transplant 28:352-359

42. Oz OK, Hajibeigi A, Howard K, Cummins CL, van Abel M, Bindels RJ, Word RA, Kuro-o M, Pak CY, Zerwekh JE 2007 Aromatase deficiency causes altered expression of molecules critical for calcium reabsorption in the kidneys of female mice *. J Bone Miner Res 22:1893-1902

43. Hsu SC, Huang SM, Lin SH, Ka SM, Chen A, Shih MF, Hsu YJ 2014 Testosterone increases renal anti-aging klotho gene expression via the androgen receptor-mediated pathway. Biochem J 464:221-229 
44. Olauson H, Lindberg K, Amin R, Sato T, Jia T, Goetz R, Mohammadi M, Andersson G, Lanske B, Larsson TE 2013 Parathyroid-specific deletion of Klotho unravels a novel calcineurin-dependent FGF23 signaling pathway that regulates PTH secretion. PLoS Genet 9:e1003975

45. Fan Y, Liu W, Bi R, Densmore MJ, Sato T, Mannstadt M, Yuan Q, Zhou X, Olauson H, Larsson TE, Toka HR, Pollak MR, Brown EM, Lanske B 2018 Interrelated role of Klotho and calcium-sensing receptor in parathyroid hormone synthesis and parathyroid hyperplasia. Proc Natl Acad Sci U S A 115:E3749-E3758

46. Takenaka T, Inoue T, Miyazaki T, Hayashi M, Suzuki H 2016 Xeno-Klotho Inhibits Parathyroid Hormone Signaling. J Bone Miner Res 31:455-462

47. Hu MC, Shi M, Cho HJ, Adams-Huet B, Paek J, Hill K, Shelton J, Amaral AP, Faul C, Taniguchi M, Wolf M, Brand M, Takahashi M, Kuro OM, Hill JA, Moe OW 2015 Klotho and phosphate are modulators of pathologic uremic cardiac remodeling. J Am Soc Nephrol 26:1290-1302

48. Billington EO, Gamble GD, Bristow S, Reid IR 2017 Serum phosphate is related to adiposity in healthy adults. Eur J Clin Invest 47:486-493

49. Zaheer S, de Boer IH, Allison M, Brown JM, Psaty BM, Robinson-Cohen C, Michos ED, Ix JH, Kestenbaum B, Siscovick D, Vaidya A 2017 Fibroblast Growth Factor 23, Mineral Metabolism, and Adiposity in Normal Kidney Function. J Clin Endocrinol Metab 102:1387-1395

50. Bolland MJ, Grey AB, Ames RW, Horne AM, Gamble GD, Reid IR 2006 Fat mass is an important predictor of parathyroid hormone levels in postmenopausal women. Bone 38:317-321

51. Grethen E, Hill KM, Jones R, Cacucci BM, Gupta CE, Acton A, Considine RV, Peacock M 2012 Serum leptin, parathyroid hormone, 1,25-dihydroxyvitamin D, fibroblast growth factor 23, bone alkaline phosphatase, and sclerostin relationships in obesity. J Clin Endocrinol Metab 97:1655-1662 
Figure 1. Distribution of soluble serum $\alpha$-klotho in study participants. Panels A) - D) show density plots (y-axes) representing the probability density function for the kernel density estimation. In addition, histograms corresponding to frequencies are overlaid. A) Kernel density plots of soluble $\alpha$-klotho serum levels (pmol/L) in entire study population. B) Distribution after square root transformation in entire study population. C) Kernel density plots of soluble $\alpha$ klotho serum levels separated by sex (men: blue, women: red). D) Distribution after square root transformation separated by sex (men: blue, women: red). E) Soluble $\alpha$-klotho levels are higher in women (median $15.3 \mathrm{pmol} / \mathrm{L}, 25^{\text {th }}-75^{\text {th }}$ percentile $10.0-22.0 \mathrm{pmol} / \mathrm{L}$ ) than men (median 13.9 $\mathrm{pmol} / \mathrm{L}, 25^{\text {th }}-75^{\text {th }}$ percentile $\left.\left.9.9-20.0 ; P=0.018\right) . F\right)$ Linear regression function of the associations of eGFRcr with square root transformed soluble serum $\alpha$-klotho. The shadowed area represents the $95 \%$ confidence interval of the regression line.

Figure 2. Association of PTH and plasma phosphate with soluble serum $\alpha$-klotho. Multivariable regression models in Table 2 are visualized to illustrate the relationship between the explanatory variable of interest while holding the effect of all other covariables in the model constant. Solid lines represent regression lines. A) Association of PTH with soluble serum $\alpha-$ klotho depending on sex. B) Association of plasma phosphate with soluble serum $\alpha$-klotho depending on age. Study participants were divided into three equal sized groups belonging to the nearest class of age.

Figure 3. Influence of soluble serum $\alpha$-klotho on the association of eGFRcr with 1,25-OHVitamin D3 and on the association of body mass index with plasma phosphate. Multivariable regression models in Table 3 are visualized to illustrate the relationship between the explanatory variable of interest while holding the effect of all other covariables in the model constant. Solid lines represent regression lines. A) Influence of soluble serum $\alpha$-klotho on the association of eGFRcr with 1,25-OH-Vitamin D3. B) Influence of soluble serum $\alpha$-klotho on 
the association of body mass index with plasma phosphate. Study participants were divided into three equal sized groups belonging to the nearest class of soluble serum $\alpha$-klotho levels.

Table 1. Participants' characteristics. Categorical variables are described by number of participants $\mathrm{N}(\%)$, continuous variables are described by their mean \pm standard deviation (SD) and range or by their median; $25^{\text {th }}-75^{\text {th }}$ percentile and range. Abbreviations: eGFRcr: glomerular filtration rate estimated creatinine Equation CKD-EPI 2009; BSA: body surface area, FGF23: fibroblast growth factor 23, PTH: parathyroid hormone, RU: relative unit.

\section{Table 2. Associations between predictor variables of interest with square-root} transformed serum soluble $\alpha$-klotho. For each predictor variable the results of an univariable and of a multivariable model are shown. Number of participants $(N)$, beta coefficients $(\beta), 95 \%$ confidence intervals $(95 \% \mathrm{CI})$ and $P$ values are indicated for the predictor variables of interest and in multivariable models also for significant interactions.

Table 3. Associations between the predictor variable serum soluble $\alpha$-klotho with laboratory parameters of calcium-phosphate metabolism. For each outcome variable the results of an univariable and of a multivariable model are shown. Number of participants $(\mathrm{N})$, beta coefficients $(\beta), 95 \%$ confidence intervals $(95 \% \mathrm{CI})$ and $P$ values are indicated for serum soluble $\alpha$-klotho in univariable models and in multivariable models also for significant interactions with serum soluble $\alpha$-klotho. 
Table 1.

\begin{tabular}{|c|c|c|c|}
\hline Parameters & $\mathbf{N}$ & $\begin{array}{c}\text { Median; } 25^{\text {th }}-75^{\text {th }} \\
\text { or Mean } \pm \text { SD } \\
\end{array}$ & Range \\
\hline Women, $\mathrm{N}(\%)$ & 912 & $477(52.3)$ & \\
\hline Age, y & 912 & $45.7 ; 30.2-58$ & $18-90$ \\
\hline Body mass index, $\mathrm{kg} / \mathrm{m}^{2}$ & 911 & $24 ; 21.6-27.1$ & $15.6-45.8$ \\
\hline eGFRcr, $\mathrm{ml} / \mathrm{min}$ per $1.73 \mathrm{~m}^{2} \mathrm{BSA}$ & 906 & $98.4 ; 87.2-110$ & $38.1-151$ \\
\hline $38-60$ & 21 & $2.3 \%$ & \\
\hline $60-70$ & 42 & $4.6 \%$ & \\
\hline $70-80$ & 73 & $8.1 \%$ & \\
\hline $80-90$ & 136 & $15 \%$ & \\
\hline $90-100$ & 215 & $23.7 \%$ & \\
\hline $100-110$ & 194 & $21.4 \%$ & \\
\hline $110-120$ & 130 & $14.3 \%$ & \\
\hline $120-130$ & 74 & $8.2 \%$ & \\
\hline $130-151$ & 21 & $2.3 \%$ & \\
\hline Soluble $\alpha$-klotho, pmol/L & 912 & $15 ; 10-21$ & $1.8-51.2$ \\
\hline PTH, pg/ml & 909 & $36.9 ; 29.6-45$ & $8.8-108$ \\
\hline 25-OH-Vitamin D3, nmol/L & 908 & $47 ; 34-62$ & $5.5-163$ \\
\hline $1,25-(\mathrm{OH})_{2}$ Vitamin $\mathrm{D}_{3}, \mathrm{pmol} / \mathrm{L}$ & 846 & $92 ; 70-116$ & $5.5-217$ \\
\hline FGF23, RU/ml & 912 & $78.6 ; 63-103$ & $18-1078$ \\
\hline Phosphate plasma, $\mathrm{mmol} / \mathrm{L}$ & 904 & $1.04 \pm 0.166$ & $0.55-1.66$ \\
\hline Calcium plasma, $\mathrm{mmol} / \mathrm{L}$ & 905 & $2.33 ; 2.27-2.38$ & $2.05-2.69$ \\
\hline Phosphate urine $\mathrm{mmol} / 24 \mathrm{~h}$ & 890 & $25.3 ; 20.2-31.9$ & $2.77-101$ \\
\hline Calcium urine, $\mathrm{mmol} / 24 \mathrm{~h}$ & 887 & $3.66 ; 2.46-5.22$ & $0.275-16.4$ \\
\hline
\end{tabular}


Table 2.

\begin{tabular}{|c|c|c|c|c|c|c|c|c|}
\hline \multirow[b]{2}{*}{ Predictor variable } & \multicolumn{4}{|c|}{ Univariable Models } & \multicolumn{4}{|c|}{ Multivariable Models } \\
\hline & $\mathbf{N}$ & $\boldsymbol{\beta}$ & $95 \% \mathrm{CI}$ & $P$ value & $\mathbf{N}$ & $\boldsymbol{\beta}$ & $95 \% \mathrm{CI}$ & $P$ value \\
\hline Age, $y$ & 912 & -0.0038 & -0.0068 to -0.0007 & 0.015 & 905 & -0.0009 & -0.00560 .0038 & 0.70 \\
\hline Sex, women & 912 & 0.1507 & $0.0484-0.2534$ & 0.0035 & 905 & 0.1620 & $0.0586-0.2669$ & 0.0021 \\
\hline eGFRcr, $\mathrm{mL} / \mathrm{min}$ per $1.73 \mathrm{~m}^{2} \mathrm{BSA}$ & 906 & 0.0044 & $0.0013-0.0075$ & 0.0051 & 905 & 0.0024 & $-0.0022-0.007$ & 0.31 \\
\hline PTH, pg/mL & 909 & -0.0032 & $-0.0074-0.001$ & 0.13 & 902 & 0.0063 & $0.0001-0.0125$ & 0.049 \\
\hline interaction with sex & & & & & & -0.0111 & -0.0188 to -0.0035 & 0.0045 \\
\hline $1,25-(\mathrm{OH})_{2}$ Vitamin $\mathrm{D}_{3}, \mathrm{pmol} / \mathrm{L}$ & 846 & 0.0000 & $-0.0017-0.0018$ & 0.99 & 840 & -0.0006 & $-0.0023-0.0012$ & 0.55 \\
\hline FGF23, RU/mL & 912 & 0.0001 & $-0.0005-0.0008$ & 0.69 & 905 & 0.0002 & $-0.0005-0.0008$ & 0.64 \\
\hline Phosphate plasma, $\mathrm{mmol} / \mathrm{L}$ & 904 & 0.0702 & $-0.2671-0.4056$ & 0.68 & 903 & -0.0648 & $-0.4120-0.2797$ & 0.71 \\
\hline interaction with age & & & & & & -0.0220 & -0.0387 to -0.0050 & 0.011 \\
\hline age in the model & & & & & & -0.0007 & $-0.0054-0.0040$ & 0.76 \\
\hline Calcium, mmol/L & 905 & 0.6672 & $0.0265-1.3091$ & 0.042 & 904 & 0.3957 & $-0.2358-1.0263$ & 0.22 \\
\hline Fractional excretion of calcium, $\%$ & 876 & -0.0294 & $-0.0564-0.0482$ & 0.31 & 875 & -0.0123 & $-0.0544-0.0463$ & 0.66 \\
\hline
\end{tabular}

Page 25 of 29 
Table 3.

\begin{tabular}{|c|c|c|c|c|c|c|c|c|}
\hline \multirow[b]{2}{*}{ Outcome variable } & \multicolumn{4}{|c|}{ Univariable Models } & \multicolumn{4}{|c|}{ Multivariable Models } \\
\hline & $\mathbf{N}$ & $\beta$ & $95 \% \mathrm{CI}$ & $P$ value & $\mathbf{N}$ & $\beta$ & $95 \% \mathrm{CI}$ & $P$ value \\
\hline eGFRcr, $\mathrm{mL} / \mathrm{min}$ per $1.73 \mathrm{~m}^{2} \mathrm{BSA}$ & 906 & 3.474 & $1.274-5.662$ & 0.0018 & 905 & 0.8742 & $-0.7328-2.4849$ & 0.29 \\
\hline $\mathrm{PTH}, \mathrm{pg} / \mathrm{mL}$ & 909 & -0.0017 & $-0.0045-0.0012$ & 0.26 & 902 & 0.0004 & $-0.0024-0.0032$ & 0.80 \\
\hline 25-OH-Vitamin $\mathrm{D}_{3}, \mathrm{nmol} / \mathrm{L}$ & 908 & 0.0025 & $-0.0107-0.0158$ & 0.71 & 901 & -0.0022 & $-0.0162-0.0116$ & 0.75 \\
\hline $1,25-(\mathrm{OH})_{2}$ Vitamin $\mathrm{D}_{3}, \mathrm{pmol} / \mathrm{L}$ & 846 & -0.0073 & $-0.0227-0.0082$ & 0.36 & 840 & $\begin{array}{c}-0.0067 \\
-0.0009 * 1 \\
0.0889 * 2\end{array}$ & $\begin{array}{c}-0.0226-0.0092 \\
-0.0017 \text { to }-0.0009 * 1 \\
-0.0006-0.0184 * 2\end{array}$ & $\begin{array}{r}0.41 \\
0.029 * 1 \\
0.068 * 2\end{array}$ \\
\hline FGF23, RU/mL & 912 & 0.0010 & $-0.003-0.005$ & 0.63 & 905 & 0.0014 & $-0.0029-0.0057$ & 0.54 \\
\hline Phosphate plasma, $\mathrm{mmol} / \mathrm{L}$ & 904 & -0.0005 & $-0.0019-0.0009$ & 0.49 & 903 & $\begin{array}{c}-0.0005 \\
0.0004^{\# 1} \\
-0.0043^{\# 2}\end{array}$ & $\begin{array}{c}-0.0019-0.0010 \\
0.0001-0.0006^{\# 1} \\
-0.0068 \text { to }-0.0018^{\# 2}\end{array}$ & $\begin{array}{r}0.53 \\
0.011^{\# 1} \\
0.00066^{\# 2}\end{array}$ \\
\hline Calcium, mmol/L & 905 & 0.0002 & $0-0.0003$ & 0.036 & 904 & 0.0001 & $-0.0001-0.0002$ & 0.35 \\
\hline Phosphate urine, $\mathrm{mmol} / 24 \mathrm{~h}$ & 890 & -0.0028 & $-0.0106-0.0048$ & 0.47 & 883 & -0.0009 & $-0.0083-0.0065$ & 0.81 \\
\hline Fractional excretion of phosphate, $\%$ & 881 & 0.0003 & $-0.0051-0.0056$ & 0.92 & 880 & 0.0012 & $-0.0037-0.0061$ & 0.62 \\
\hline TmP/GFR, mmol/L & 881 & -0.0002 & $-0.0011-0.0007$ & 0.67 & 880 & -0.0004 & $-0.0012-0.0005$ & 0.40 \\
\hline Calcium urine, $\mathrm{mmol} / 24 \mathrm{~h}$ & 887 & -0.0042 & $-0.0089-0.0004$ & 0.075 & 880 & -0.0012 & $-0.0061-0.0038$ & 0.64 \\
\hline Fractional excretion of calcium, $\%$ & 876 & -0.0024 & $-0.0056-0.0007$ & 0.13 & 875 & -0.0009 & $-0.0042-0.0025$ & 0.61 \\
\hline
\end{tabular}

*1 for interaction between soluble serum $\alpha$-klotho and eGFRcr, ${ }^{2}$ for eGFRcr in the model

${ }^{\# 1}$ for interaction between soluble serum $\alpha$-klotho and BMI, ${ }^{\# 2}$ for BMI in the model 
Figure 1.

A

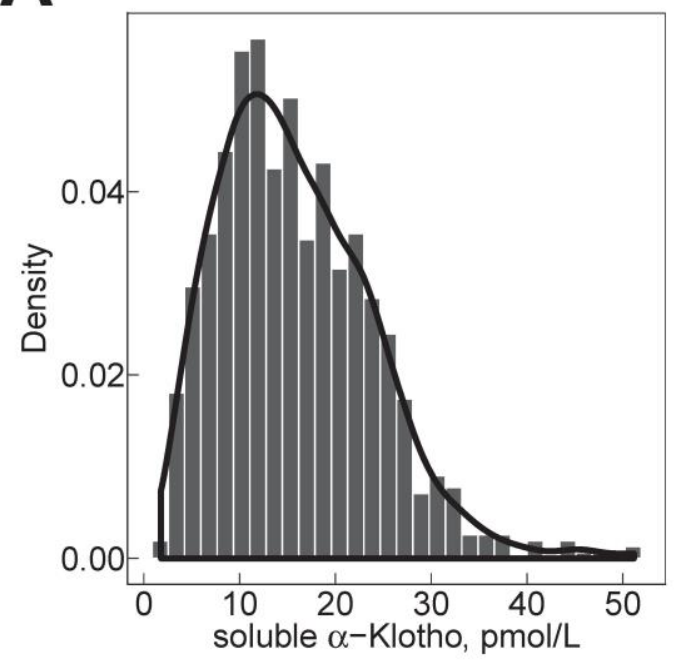

C

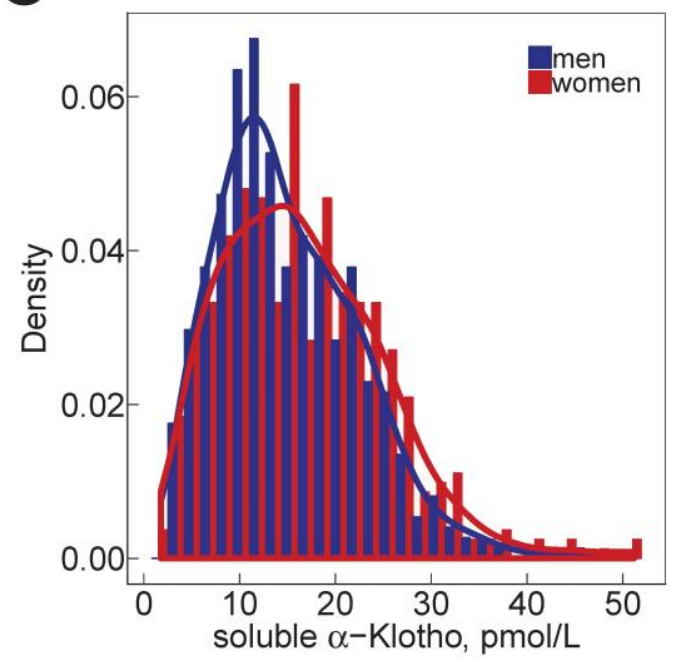

E

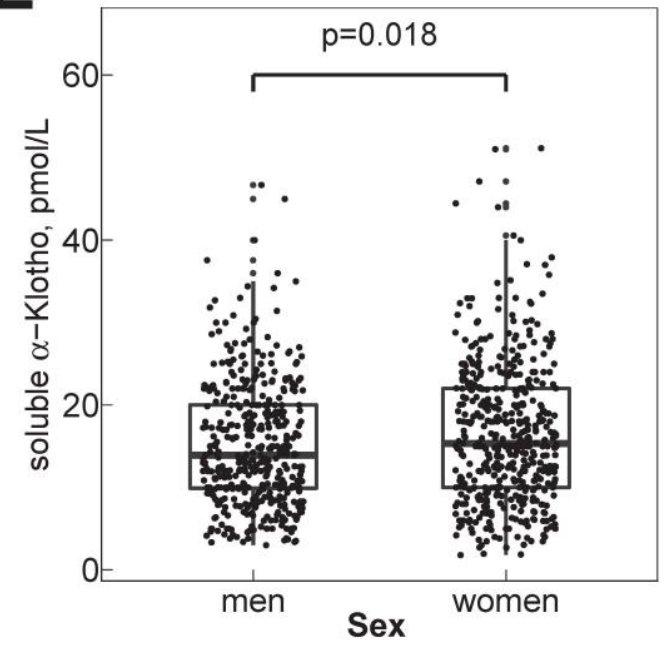

B

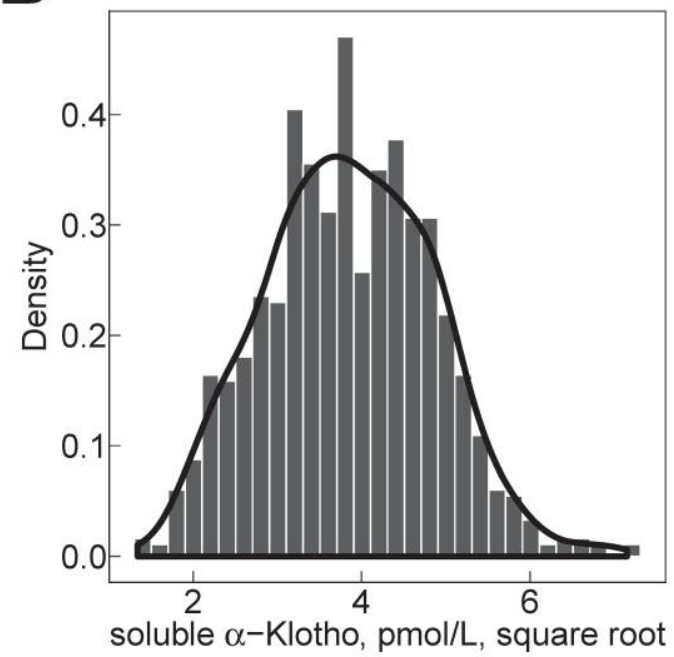

D
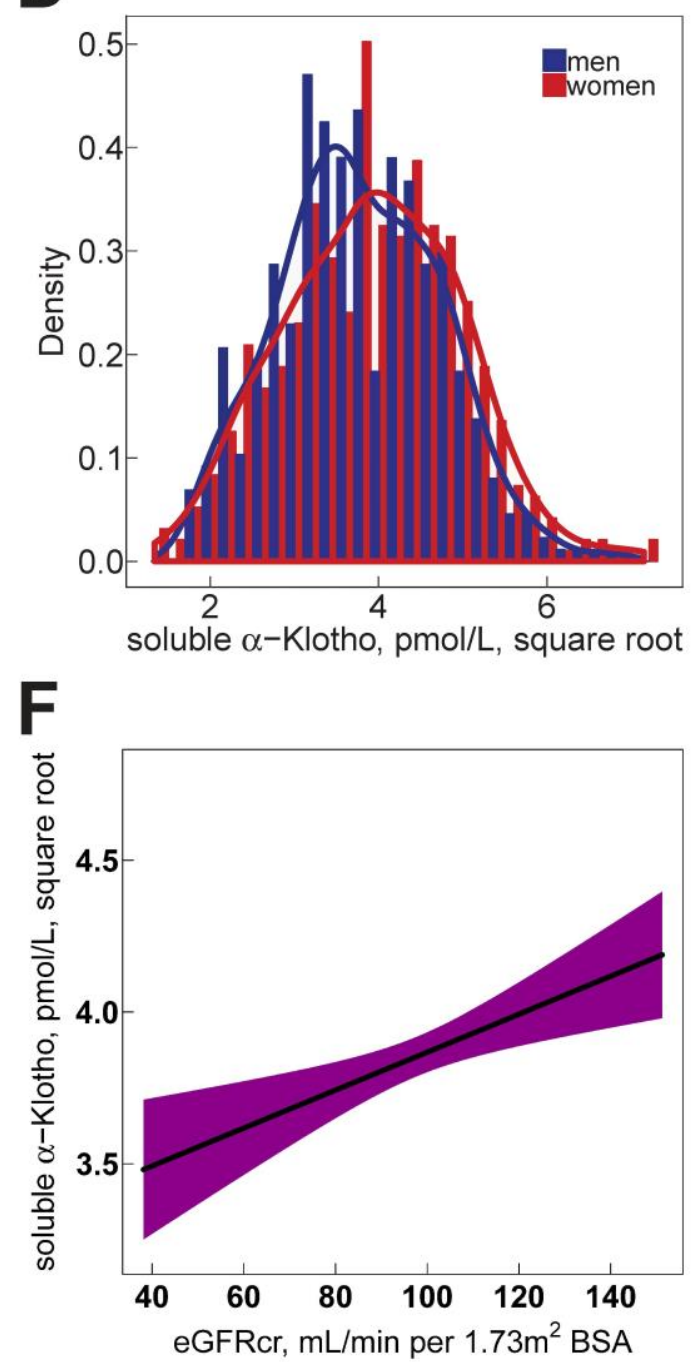
Figure 2.
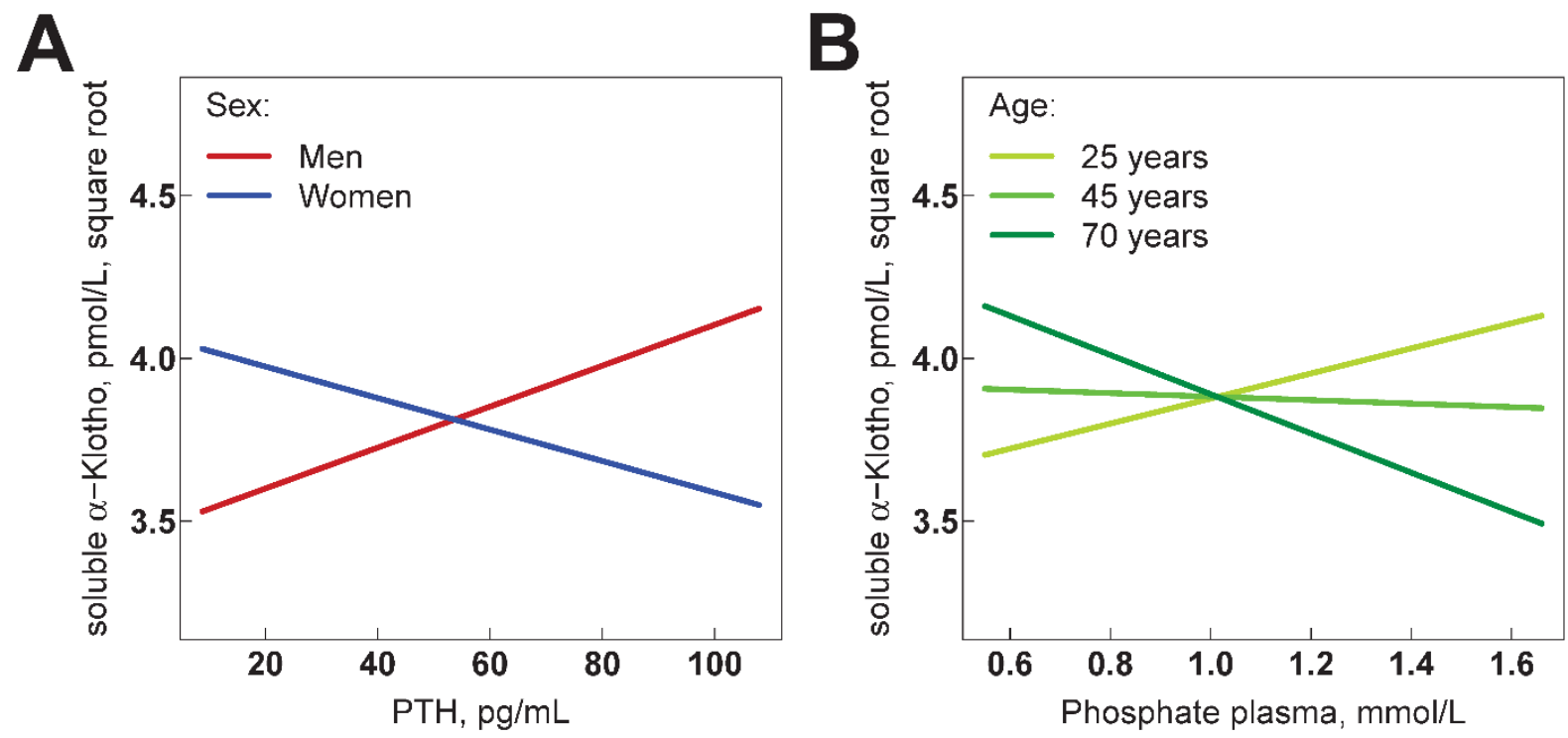

Page 28 of 29 
Figure 3.
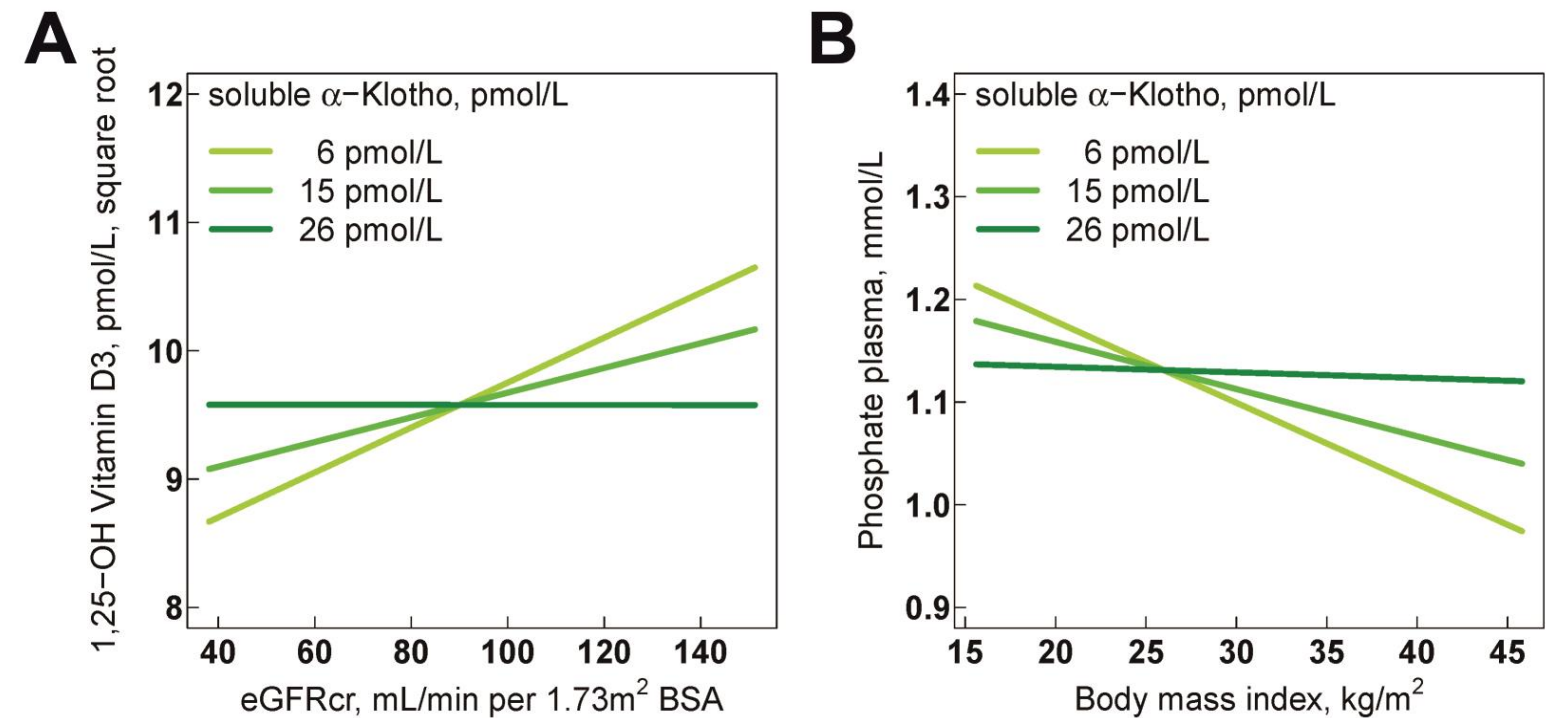

Page 29 of 29 